OPEN ACCESS

Edited by:

Soraia Garcês,

University of Madeira, Portugal

Reviewed by:

Lunthita M. Duthely,

University of Miami Health Systems,

United States

Inês Ferraz,

Centro de Investigação em Estudos

da Criança, Portugal

*Correspondence:

Natalia Czyżowska

natalia.czyzowska@up.krakow.p

Specialty section:

This article was submitted to

Positive Psychology,

a section of the journal

Frontiers in Psychology

Received: 31 July 2021

Accepted: 08 December 2021

Published: 04 January 2022

Citation:

Czyżowska N and Gurba E (2022)

Enhancing Meaning in Life

and Psychological Well-Being Among

a European Cohort of Young Adults

via a Gratitude Intervention.

Front. Psychol. 12:751081.

doi: 10.3389/fpsyg.2021.751081

\section{Enhancing Meaning in Life and Psychological Well-Being Among a European Cohort of Young Adults via a Gratitude Intervention}

\author{
Natalia Czyżowska ${ }^{1 *}$ and Ewa Gurba ${ }^{2}$ \\ ${ }^{1}$ Department of Pedagogy and Psychology, Institute of Psychology, Pedagogical University of Kraków, Kraków, Poland, \\ 2 Department of Philosophy, The Pontifical University of John Paul II, Kraków, Poland
}

Background: Strengthening the sense of meaning in life and psychological well-being brings benefits for mental health. The group particularly vulnerable to mental problems are young adults, therefore the aim of our research was to explore how a gratitude intervention will affect the sense of meaning in life, psychological well-being, general health and perceived stress among them. The research also took into account the issue of expressing gratitude.

Method: The study involved 80 young adults (58 women and 22 men) who were randomly assigned to the experimental group that filled out the specially prepared diaries for a week (participants were asked to list three things for which they feel grateful, to whom they are grateful and if and how they expressed their gratitude) or the control group. Participants completed the Meaning in Life Questionnaire (MLQ), the General Health Questionnaire - 28 (GHQ-28), the Perceived Stress Scale (PSS), and the Ryff Scales of Psychological Well-Being (PWBS) twice (before and after intervention).

Results: In the experimental group significant increases were observed in three areas of psychological well-being: environmental mastery, relationships with others and purpose in life. The significant decrease was also noted in anxiety/insomnia and depression symptoms as well as in perceived stress. There were no differences in the level of meaning in life. There was a positive relationship between expressing gratitude and meaning in life and psychological well-being.

Conclusion: Proposed gratitude intervention has the potential to enhance psychological well-being among young adults, however, it may not be effective in enhancing meaning in life.

Keywords: meaning in life, psychological well-being, young adults, gratitude, intervention, mental health

\section{INTRODUCTION}

As research results have shown, prevention focusing solely on reducing the risk of mental disorders is insufficient and it is necessary to look for various ways to promote mental health (Keyes, 2007; Keyes et al., 2010) which is one of the goals of positive psychology. Positive psychology, in contrast to the general approach that pay a lot of attention to psychological disorders, maladaptive sides 
of human functioning and negative effects of stress, focuses on human virtues and positive traits. According to its pioneers, understanding and promoting the factors that allow individuals to thrive, is necessary to effectively prevent and treat psychopathology (Seligman and Csikszentmihalyi, 2000). This seems particularly important considering that mental health is more than the absence of symptoms of mental illness. According to the definition of the World Health Organization (2004), it is a state of well-being in which the individual knows his or her strengths and can cope with challenges of everyday life and contribute to the growth of his or her community. Mental health promotion should therefore include activities that could potentially enhance the sense of well-being. Increasing well-being is one of the basic goals of positive psychology interventions (PPIs; Carr et al., 2020), which do not completely replace traditional clinical psychological interventions, but complement them (Seligman and Csikszentmihalyi, 2000). In recent years there has been a significant increase of interest in such interventions (Weiss et al., 2016; Schotanus-Dijkstra et al., 2017; Koydemir et al., 2021; van Agteren et al., 2021). Young adults (between 18 and 29 years of age) appear to be one of the groups for whom such mental health promoting interventions should particularly be undertaken. As epidemiological data has shown the prevalence of any mental disorder among young adults was higher than in any other age group during the course of 12 months (Alonso et al., 2004; Ishikawa et al., 2018; Stagnaro et al., 2018; National Health Institute, 2019). This may be due to the fact that people in this age group are in a specific developmental period, transitioning between adolescence and adulthood, and the challenges associated with it may increase anxiety, insecurity and confusion (Arnett, 2014; Arnett et al., 2014).

In the psychological literature, there are two main approaches to well-being: hedonistic (which concentrates on subjective wellbeing understood as life satisfaction, associated with high levels of positive emotions and low levels of negative emotions) (Deci and Ryan, 2008) and eudemonistic (which concerns psychological well-being encompassing six dimensions of wellness which are related to optimal functioning: self-acceptance, positive relations with others, autonomy, environmental mastery, purpose in life and personal growth) (Ryff, 1995; Ryff and Keyes, 1995). One of the important elements of well-being is to perceive one's own life as meaningful and valuable (Greenberg and Arndt, 2012). A sense of meaning in life is associated with better stress coping (Hooker et al., 2018), lower intensity of anxiety and depression symptoms (Disabato et al., 2017; Korkmaz and Güloğlu, 2021), and moreover, is regarded as a protective factor for mental health, e.g., reducing the severity of suicidal tendencies (Lew et al., 2020). Having meaning in life certainly brings many benefits to the functioning of the individual. However, as researchers point out, it is difficult to modify it directly, hence the idea to do so indirectly, e.g., by strengthening gratitude (Kleiman et al., 2013). It is known that both gratitude and meaning in life are positively related to psychological well-being (Krok, 2015; Kardas et al., 2019). Experiencing gratitude may contribute to living a meaningful life, as it is related, for example, to having a purpose in life and assessing one's own life as more significant
(Wood et al., 2009). Gratitude, understood in terms of life orientation, may also increase recognition for one's own existence (Ryff and Singer, 1998). Research has also shown that meaning in life mediates the relationship between gratitude and wellbeing (Datu and Mateo, 2015). Furthermore, there is a negative relationship between gratitude and both depression and suicidal ideations (Liang et al., 2020; Lin, 2021) and those who are more grateful have greater life satisfaction (Xiang and Yuan, 2021). It is worth emphasizing that in the previous research on the relationship between gratitude, sense of meaning in life and well-being, the experience of gratitude was primarily measured. The researchers point out, however, that expressing gratitude, instead just experiencing it, may bring even more benefits to the individual (Lambert et al., 2010). Research results obtained so far show gratitude interventions increasing gratitude in groups of young adults (Baumsteiger et al., 2019; Koay et al., 2020). There is also a single study that shows that gratitude interventions can strengthen purpose in life, both in terms of its search and identification, in this age group (Bronk et al., 2019), which allows to assume that they may also have the potential to strengthen the sense of meaning in life. However, there is no data that would indicate that.

The first aim of our research was to examine whether a gratitude intervention would enhance the sense of meaning in life and psychological well-being as well as contribute to the reduction of undesirable symptoms such as anxiety and depression. It was decided to focus on the group of young adults (between 18 and 29 years of age) as the group particularly vulnerable to mental problems. The second aim of this study was to investigate the relationship between expressing gratitude, meaning in life, general health, perceived stress and psychological well-being.

\section{METHOD}

\section{Procedure}

The research was designed as a pretest - posttest control group study. Each participant met the researcher twice. During the first meeting, participants drew an envelope with a code assigning them to one of two groups - with or without intervention (control group). The envelopes with the codes were arranged in a random order. Participants from intervention group received specially prepared paper diaries in which they were to write down every day for 7 days three things for which they feel grateful, to whom they are grateful and if and how they expressed their gratitude in these situations. In order to not influence the answers given in the questionnaires, the respondents were not informed that the intervention might affect their sense of meaning in life or well-being before the end of the study. Participants from control group did not perform any additional activities during the week. A week later, a second meeting with the researcher took place. One could receive a salary of $\$ 9$ for participating in the study.

The study was conducted in accordance with the principles of the Declaration of Helsinki. Participants received oral and written information about the study and signed informed consent to participate in the study. The study was voluntary 
and anonymous, participants could withdraw at any time without giving any reason. The project was approved and financed from the funds earmarked for young scientists and doctoral students at the Faculty of Philosophy of the Jagiellonian University in Kraków.

\section{Participants}

Eighty young adults (56 women and 22 men) between 18 and 25 years old participated in the study. The respondents were recruited via e-mail and through advertisements posted on student forums of three universities in Kraków. The study involved people who were not undergoing psychiatric treatment. People who experienced a traumatic event in the previous year (such as a divorce, accident, death of a loved one) were excluded from the study due to the fact that it could significantly affect their sense of meaning in life. The research was conducted from January to October 2019. The results of a priori analysis of statistical power for differences between dependent means (matched pairs) with effect size defined as $q=0.5$ showed that for error probability set as $\alpha=0.05$ and power set as $1-\beta=0.9$ the minimum required sample size was 36 . The results of a priori analysis of statistical power calculated for linear multiple regression with effect size defined as $f^{2}=0.5$ showed that for error probability set as $\alpha=0.05$, power set as $1-\beta=0.9$ and number of predictors set as 3 the minimum required sample size was 33 . Detailed information on the experimental group and the control group are presented in Table 1.

\section{Measures}

The respondents completed all the questionnaires twice (except for the short demographic questionnaire which included

TABLE 1 | Characteristics of the sample $(n=80)$.

\begin{tabular}{|c|c|c|c|c|}
\hline & \multicolumn{2}{|c|}{ Group with intervention } & \multicolumn{2}{|c|}{ Control group } \\
\hline & $M$ & SD & $M$ & SD \\
\hline \multirow[t]{2}{*}{ Age } & 20.60 & 1.83 & 21.25 & 2.29 \\
\hline & $n$ & $\%$ & $n$ & $\%$ \\
\hline \multicolumn{5}{|l|}{ Sex } \\
\hline Male & 7 & 17.5 & 15 & 37.5 \\
\hline Female & 33 & 82.5 & 23 & 62.5 \\
\hline \multicolumn{5}{|l|}{ Place of residence } \\
\hline Town & 27 & 67 & 35 & 87.5 \\
\hline Village & 13 & 33 & 5 & 12.5 \\
\hline \multicolumn{5}{|l|}{ Marital status } \\
\hline Single & 26 & 65 & 17 & 43 \\
\hline Informal relationship & 14 & 35 & 23 & 57 \\
\hline Married & 0 & 0 & 0 & 0 \\
\hline \multicolumn{5}{|l|}{ Children } \\
\hline Yes & 0 & 0 & 0 & 0 \\
\hline No & 40 & 100 & 40 & 100 \\
\hline \multicolumn{5}{|l|}{ Job } \\
\hline Yes & 11 & 27.5 & 14 & 36 \\
\hline No & 29 & 72.5 & 26 & 64 \\
\hline
\end{tabular}

questions about gender, marital and parental status, place of residence, employment status): before the start of the intervention and after 1 week (i.e., at the end of the intervention). All questionnaires are commonly used in scientific research and have sufficient psychometric values.

\section{Meaning in Life Questionnaire}

Meaning in Life Questionnaire by Steger et al. (2006) contains 10 questions rated on a 7-point Likert scale (from "absolutely untrue" to "absolutely true"). It consists of two subscales: presence of meaning in life and search of meaning in life, which allow to measure the sense of meaning in life in the present and in the future. The research used the Polish version of the questionnaire. Cronbach's alpha index for the subscale measuring the presence of meaning in life is 0.86 and for the subscale used to measure sense-seeking is 0.87 (Kossakowska et al., 2013).

\section{General Health Questionnaire-28}

General Health Questionnaire-28 by Goldberg and Hillier (1979) consists of four subscales (7 items each) allowing the measurement of: the severity of somatic symptoms (subscale A), anxiety and insomnia (subscale B), social dysfunction (subscale C), symptoms of depression (subscale D). The severity of symptoms is rated by the subject on a 4-point scale (from "not at all" to "much more than usual"). Polish adaptation of the questionnaire was used in the study where Cronbach's alpha index for subscales ranges from 0.82 to 0.93 (Makowska and Merecz, 2001) Perceived Stress Scale (PSS).

Perceived Stress Scale by Cohen et al. (1983) is used to measure feelings and reactions related to everyday problems and ways of coping. It consists of 10 questions rated on a scale from 0 - "never" to 4 - "very often." The study used the Polish adaptation of the questionnaire where Cronbach's alpha index was 0.86 and test-retest reliability (4-week period) equaled 0.72 (Juczyński and Ogińska-Bulik, 2009).

\section{Ryff's Psychological Well-Being Scales}

Psychological Well-Being Scales by Ryff and Keyes (1995) are used to measure six dimensions of psychological well-being in the eudemonistic approach: autonomy, self-acceptance, positive relationships with others, personal development, life goal and environmental mastery. The scales consist of 84 items rated from 1 to 6 (1-"I strongly disagree"; 3-"I rather disagree," 6-"I strongly agree"). As in the case of other tools, the Polish scale adaptation was used. For each subscale Cronbach's alpha index is over 0.70 (Karaś and Cieciuch, 2017).

\section{Expressing Gratitude Index}

Inquiring whether the participants expressed gratitude allowed us to calculate the rate of expressing gratitude. For each situation in which the respondent expressed gratitude in some way, 1 point was awarded - thus, the maximum was 21 points (three daily situations in which the respondent could express gratitude multiplied by 7 days of the intervention).

\section{Statistical Analyses}

The distribution of all variables (except for depression symptoms) was approximately normal as skewness and kurtosis of the data 
were between -1 and +1 and $z$ value was in the range of \pm 1.96 which is sufficient to establish normality of the data (Mishra et al., 2019). To compare the results obtained in the pre-test and post-test, paired samples Student's $t$-tests were carried out. Due to the skewness of the distribution of depression symptoms, the Wilcoxon Test was used to compare the differences between first and second measurement. To investigate the relationship between expressing gratitude and other variables, the Pearson correlation coefficient was used. The error terms were normally distributed, as well as the other criteria of the regression analysis were met, which allowed to perform it (Flatt and Jacobs, 2019). All the statistical procedures were computed using STATISTICA 13.

\section{RESULTS}

In the experimental group, significant increases were noted between pretest and posttest in the following areas of psychological well-being: environmental mastery, positive relationships with others and purpose in life. The significant decrease was also observed on two GHQ-28 subscales: the B subscale (anxiety/insomnia) and the D subscale (depression symptoms $)(T=24.0 ; z=2.85 ; p=0.004)$ and in the area of perceived stress. There were no differences in the level of meaning in life. Detailed results are provided in Table 2.

In the control group, the level of perceived stress increased after a week, as well as the results on GHQ-28 subscales: the $\mathrm{B}$ subscale (anxiety/insomnia) and the $\mathrm{C}$ subscale (social dysfunction). There were no differences in the level of meaning in life and psychological well-being. Detailed results are provided in Table 3.
There was a positive relationship between expressing gratitude and meaning in life and psychological well-being, and a negative relationship between anxiety/insomnia, social dysfunction and depression symptoms. Detailed results are provided in Table 4.

The overall model $F$ test for the multiple regression conducted to predict the global psychological well-being from meaning in life, perceived stress and general health was significant $F_{(3,76)}=8.45, p=0001, R^{2}=0.327, R_{\text {adj }}^{2}=0.29$, however, only meaning in life $(\beta=0.35 ; p=0.005)$ and perceived stress $(\beta=-0.33 ; p=0.007)$ were statistically significant predictors.

\section{DISCUSSION}

The findings demonstrated that the gratitude intervention improved psychological well-being, specifically in the areas of environmental mastery, positive relationships with others and purpose in life among a sample of young adults studying in Europe. This is consistent with the results obtained by other researchers, which indicate that gratitude interventions may increase well-being in this age group. However, it is worth emphasizing that most of these studies concerned life satisfaction, not the six dimensions of psychological well-being (Lyubomirsky et al., 2011; Watkins et al., 2015; Gabana et al., 2019). The results of our study allow us to suppose that gratitude interventions may be useful both in the context of subjective and psychological well-being. A decrease in symptoms of anxiety/insomnia and depression was also observed in the intervention group. This is in line with other studies in which the effectiveness of gratitude interventions for anxiety and depression symptoms was tested (O'Leary and Dockray, 2015; Heckendorf et al., 2019). However, it is noted that the effectiveness of

TABLE 2 | Comparison of the level of meaning in life, general health, perceived stress and psychological well-being before and after intervention in experimental group (with intervention) $(n=40)$.

\begin{tabular}{|c|c|c|c|c|c|c|c|}
\hline & & \multicolumn{2}{|c|}{ Before intervention } & \multicolumn{2}{|c|}{ After intervention } & \multirow[t]{2}{*}{$t$} & \multirow[t]{2}{*}{$p$} \\
\hline & & $M$ & SD & $M$ & SD & & \\
\hline \multirow[t]{3}{*}{ Meaning in life (MLQ) } & Total result & 48.37 & 7.39 & 47.85 & 11.01 & 0.53 & 0.59 \\
\hline & Presence of meaning in life & 21.15 & 5.02 & 21.75 & 6.64 & -0.95 & 0.34 \\
\hline & Search of meaning in life & 27.22 & 3.66 & 26.10 & 5.57 & 1.97 & 0.06 \\
\hline \multirow{5}{*}{$\begin{array}{l}\text { General Health Questionnaire } \\
\text { (GHQ-28) }\end{array}$} & Total result & 27.05 & 10.67 & 25.34 & 14.76 & 0.57 & 0.56 \\
\hline & Somatic symptoms & 7.00 & 3.68 & 7.75 & 5.47 & -1.02 & 0.31 \\
\hline & Anxiety and insomnia & $8.00^{*}$ & 3.57 & $7.20^{*}$ & 4.30 & $2.22^{\star}$ & $0.03^{*}$ \\
\hline & Social dysfunction & 7.32 & 3.36 & 7.45 & 2.85 & -0.50 & 0.61 \\
\hline & Depression symptoms & 3.97 & 5.02 & 3.17 & 5.11 & - & - \\
\hline Perceived stress (PSS) & Total result & $20.65^{\star}$ & 6.67 & $19.00^{*}$ & 6.57 & $2.27^{*}$ & $0.02^{\star}$ \\
\hline \multirow{7}{*}{$\begin{array}{l}\text { Psychological well-being } \\
\text { (PWBS) }\end{array}$} & Total result & 57.57 & 9.48 & 57.33 & 9.15 & 0.04 & 0.96 \\
\hline & Self-acceptance & 50.97 & 14.86 & 51.75 & 16.43 & -0.89 & 0.37 \\
\hline & Positive relationships with others & $57.25^{\star \star \star}$ & 9.83 & $62.05^{\star \star \star}$ & 10.31 & $-6.14^{\star \star \star}$ & $<0.001^{\star \star \star}$ \\
\hline & Autonomy & 56.45 & 11.25 & 56.57 & 13.24 & -0.13 & 0.89 \\
\hline & Environmental mastery & $53.57^{\star \star}$ & 10.12 & $55.32^{* *}$ & 10.29 & $-2.63^{\star \star}$ & $0.01^{\star \star}$ \\
\hline & Purpose in life & $54.00^{\star \star \star}$ & 8.47 & $57.82^{\star \star \star}$ & 10.58 & -4.52 & $<0.001^{\star \star \star}$ \\
\hline & Personal growth & 63.92 & 6.99 & 63.97 & 8.22 & -0.09 & 0.92 \\
\hline
\end{tabular}

${ }^{*}$ Statistically significant results; ${ }^{*} p \leq 0.05 ;{ }^{* *} p \leq 0.01 ;{ }^{* *} p \leq 0.001$. 
TABLE 3 | Comparison of the level of meaning in life, general health, perceived stress and psychological well-being before (pretest) and after a week (posttest) in control group (without intervention) $(n=40)$.

\begin{tabular}{|c|c|c|c|c|c|c|c|}
\hline & & \multicolumn{2}{|c|}{ Pretest } & \multicolumn{2}{|c|}{ Posttest } & \multirow[t]{2}{*}{$t$} & \multirow[t]{2}{*}{$p$} \\
\hline & & $M$ & SD & $M$ & SD & & \\
\hline \multirow[t]{3}{*}{ Meaning in life (MLQ) } & Total result & 47.50 & 5.56 & 47.75 & 6.03 & -1.74 & 0.10 \\
\hline & Presence of meaning in life & 22.12 & 3.98 & 22.25 & 3.95 & -0.11 & 0.91 \\
\hline & Search of meaning in life & 25.37 & 4.52 & 26.50 & 3.89 & -1.88 & 0.07 \\
\hline \multirow{5}{*}{$\begin{array}{l}\text { General Health Questionnaire } \\
\text { (GHQ-28) }\end{array}$} & Total result & 23.33 & 9.79 & 25.00 & 7.48 & -0.39 & 0.70 \\
\hline & Somatic symptoms & 8.00 & 3.50 & 6.75 & 2.35 & 1.53 & 0.14 \\
\hline & Anxiety and insomnia & 7.75 & 3.37 & 8.75 & 3.82 & -1.41 & 0.17 \\
\hline & Social dysfunction & $6.62^{*}$ & 1.45 & $7.50^{*}$ & 0.73 & $-2.67^{\star \star}$ & $0.01^{\star *}$ \\
\hline & Depression symptoms & 1.25 & 1.23 & 0.87 & 1.20 & - & - \\
\hline Perceived stress (PSS) & Total result & $16.25^{\star}$ & 5.02 & $18.25^{\star}$ & 6.27 & $-2.48^{\star}$ & $0.02^{*}$ \\
\hline \multirow{7}{*}{$\begin{array}{l}\text { Psychological well-being } \\
\text { (PWBS) }\end{array}$} & Total result & 60.31 & 3.64 & 60.64 & 4.62 & -0.64 & 0.52 \\
\hline & Self-acceptance & 61.37 & 4.03 & 62.38 & 5.48 & -0.67 & 0.50 \\
\hline & Positive relationships with others & 59.12 & 9.05 & 58.75 & 4.84 & 0.28 & 0.78 \\
\hline & Autonomy & 58.87 & 13.24 & 57.87 & 12.37 & 0.99 & 0.33 \\
\hline & Environmental mastery & 60.00 & 5.77 & 59.37 & 4.86 & 0.67 & 0.50 \\
\hline & Purpose in life & 57.25 & 5.90 & 59.62 & 7.62 & -3.88 & 0.08 \\
\hline & Personal growth & 65.25 & 4.72 & 62.37 & 7.29 & 1.58 & 0.13 \\
\hline
\end{tabular}

*Statistically significant results; ${ }^{*} p \leq 0.05 ;{ }^{* *} p \leq 0.01$.

gratitude interventions in reducing such symptoms is limited and rather low (Cregg and Cheavens, 2021). In our research we also noted a decrease in perceived stress in the intervention group. The research results in this area are not consistent there are reports indicating that gratitude interventions are effective in reducing perceived stress (Killen and Macaskill, 2015; O'Leary and Dockray, 2015) and those that do not record significant changes (Koay et al., 2020). There were no significant differences in the level of meaning in life, so our gratitude intervention has proved ineffective in this area. There is much evidence that there is a positive relationship between

TABLE 4 | Spearman R correlations among expressing gratitude index and meaning in life, general health, perceived stress, psychological well-being $(n=40)$.

\begin{tabular}{|c|c|c|}
\hline & & $\begin{array}{l}\text { Expressing gratitude } \\
\text { index }\end{array}$ \\
\hline \multirow{3}{*}{$\begin{array}{l}\text { Meaning in life } \\
\text { (MLQ) }\end{array}$} & Total result & $0.43^{*}$ \\
\hline & Presence of meaning in life & $0.54^{\star \star}$ \\
\hline & Search of meaning in life & 0.12 \\
\hline \multirow{4}{*}{$\begin{array}{l}\text { General Health } \\
\text { Questionnaire } \\
\text { (GHQ-28) }\end{array}$} & Somatic symptoms & -0.05 \\
\hline & Anxiety and insomnia & $-0.44^{*}$ \\
\hline & Social dysfunction & $-0.39^{*}$ \\
\hline & Depression symptoms & $-0.45^{\star}$ \\
\hline $\begin{array}{l}\text { Perceived stress } \\
\text { (PSS) }\end{array}$ & Total result & -0.29 \\
\hline \multirow{7}{*}{$\begin{array}{l}\text { Psychological } \\
\text { well-being (PWBS) }\end{array}$} & Total result & $0.39^{*}$ \\
\hline & Self-acceptance & $0.46^{\star \star}$ \\
\hline & Positive relationships with others & 0.21 \\
\hline & Autonomy & 0.29 \\
\hline & Environmental mastery & $0.41^{*}$ \\
\hline & Purpose in life & $0.41^{*}$ \\
\hline & Personal growth & 0.36 \\
\hline
\end{tabular}

${ }^{*}$ Statistically significant results; ${ }^{*} p \leq 0.05 ;{ }^{* *} p \leq 0.01$. gratitude and meaning in life (Kleiman et al., 2013; Datu and Mateo, 2015; Disabato et al., 2017), but the effectiveness of gratitude interventions for meaning in life has not yet been studied. Researchers point out that meaning in life is rather stable (Steger and Kashdan, 2006), which may make it not so easy to strengthen with simple interventions. Researchers suggest that the process of creating/maintaining meaning is complex and dynamic and its strengthening should be associated with increasing one's self-awareness and the possibility of a different view of oneself and one's own life. For that reason autobiographical methods could be more useful and adequate (Reker et al., 2013). It is worth emphasizing, however, that our intervention was short, what could have contributed to the lack of the expected results. Our research also focused on expressing gratitude. There was a positive relationship between expressing gratitude and meaning in life and psychological wellbeing, and a negative relationship between expressing gratitude and symptoms of anxiety and depression Taking into account the issue of expressing gratitude, encouraging it seems important because, as researchers emphasize, the beneficial effects of gratitude can only be fully realized when it is expressed outwardly (Lambert et al., 2010). As expressing gratitude is considered one of the most potent ways to practice it (Lambert et al., 2013) people who do not share their gratitude with benefactors may not derive optimal benefits from gratitude interventions (Davis et al., 2016). Thus, it seems a good idea to implement interventions where participants would be encouraged to express their gratitude in various ways. The conducted analyses showed that meaning in life and perceived stress are predictors of psychological wellbeing. There are single reports indicating that meaning in life is a predictor of psychological well-being, although they used a different tool to measure meaning in life (García-Alandete, 2015). Studies with Iranian female adolescents showed that perceived stress is one of the predictors of psychological wellbeing, although it should be emphasized that it was a very 
specific group (Hezomi and Nadrian, 2018), so further research is needed in this area.

The study has some limitations. Firstly, the studied sample was relatively small and related to a specific developmental period, which means that the observed relationships do not necessarily apply to other age groups. The study group was also homogeneous (young, childless students) which could have influenced the obtained results. In future studies it would be worthy to verify the effectiveness of interventions among people in other life situations. Secondly, women predominated among the study participants and gender may be one of the factors moderating the effectiveness of interventions and the strength of the described relationships, so future research should ensure an equal distribution of gender among the respondents. The proposed intervention was relatively short, so extending its duration, e.g., to 14 or 21 days may be worthwhile in future studies examining its effectiveness. Moreover, follow-up study was not conducted, so it cannot be determined whether there are long-term effects of this intervention and whether the desired changes persist for a long time, which is very important in the context of preventive and therapeutic interventions.

Gratitude interventions seems to be a promising way of enhancing the sense of psychological well-being and reducing the symptoms of anxiety and depression among young adults, especially that it is very easy to implement in everyday life, it does not take much time and does not require financial outlays, although more research is needed in this area. Taking into

\section{REFERENCES}

Alonso, J., Angermeyer, M. C., Bernert, S., Bruffaerts, R., Brugha, T. S., Bryson, H., et al. (2004). Prevalence of mental disorders in Europe: results from the European Study of the Epidemiology of Mental Disorders (ESEMeD) project. Acta Psychiatr. Scand. Suppl. 420, 21-27. doi: 10.1111/j.1600-0047.2004.00327.x

Arnett, J. J. (2014). Emerging adulthood: The winding road from the late teens through the twenties. Second Edition. Oxford: Oxford University Press.

Arnett, J. J., Zukauskiené, R., and Sugimura, K. (2014). The new life stage of emerging adulthood at ages 18-29 years: Implications for mental health. Lancet Psychiatry 1, 569-576. doi: 10.1016/S2215-0366(14)00080-7

Baumsteiger, R., Mangan, S., Bronk, K. C., and Bono, G. (2019). An integrative intervention for cultivating gratitude among adolescents and young adults. J. Posit. Psychol. 14, 807-819. doi: 10.1080/17439760.2019.1579356

Bronk, K. C., Baumsteiger, R., Mangan, S., Riches, B., Dubon, V., Benavides, C., et al. (2019). Fostering purpose among young adults: Effective online interventions. J. Character Educ. 15, 21-38.

Carr, A., Cullen, K., Keeney, C., Canning, C., Mooney, O., Chinseallaigh, E., et al. (2020). Effectiveness of positive psychology interventions: a systematic review and meta-analysis. J. Posit. Psychol. 2020, 1-21. doi: 10.1080/17439760.2020. 1818807

Cohen, S., Kamarch, T., and Mermelstein, R. (1983). A global measure of perceived stress. J. Health Soc. Behav. 24, 385-396.

Cregg, D. R., and Cheavens, J. S. (2021). Gratitude interventions: effective selfhelp? A meta-analysis of the impact on symptoms of depression and anxiety. J. Happiness Stud. 22, 413-445. doi: 10.1007/s10902-020-00236-6

Datu, J. A. D., and Mateo, N. J. (2015). Gratitude and life satisfaction among Filipino adolescents: The mediating role of meaning in life. Int. J. Adv. Couns. 37, 198-206. doi: 10.1007/s10447-015-9238-3

Davis, D. E., Choe, E., Meyers, J., Wade, N., Varjas, K., Gifford, A., et al. (2016). Thankful for the little things: A meta-analysis of gratitude interventions. J. Couns. Psychol. 63, 20-31. doi: 10.1037/cou0000107

Deci, E. L., and Ryan, R. M. (2008). Hedonia, eudaimonia, and well-being: an introduction. J. Hapiness Stud. 9, 1-11. doi: 10.1007/s10902-006-9018-1 account the positive relationships between expressing gratitude and meaning in life and psychological well-being, it also seems that planned interventions should encourage people not only to experience gratitude, but also to express it.

\section{DATA AVAILABILITY STATEMENT}

The raw data supporting the conclusions of this article will be made available by the authors, without undue reservation.

\section{ETHICS STATEMENT}

Ethical review and approval was not required for the study on human participants in accordance with the local legislation and institutional requirements. The patients/participants provided their written informed consent to participate in this study.

\section{AUTHOR CONTRIBUTIONS}

NC and EG: conceptualization and writing - review and editing. NC: data curation, formal analysis, methodology, investigation, visualization, and writing - original draft. EG: supervision. Both authors contributed to the article and approved the submitted version.

Disabato, D. J., Kashdan, T. B., Short, J. L., and Jarden, A. (2017). What predicts positive life events that influence the course of depression? A longitudinal examination of gratitude and meaning in life. Cogn. Ther. Res. 41, 444-458. doi: $10.1007 /$ s10608-016-9785-x

Flatt, C., and Jacobs, R. L. (2019). Principle Assumptions of Regression Analysis: Testing, Techniques, and Statistical Reporting of Imperfect Data Sets. Adv. Dev. Hum. Resour. 21, 484-502. doi: 10.1177/1523422319869915

Gabana, N. T., Steinfeldt, J., Wong, Y. J., Chung, Y. B., and Svetina, D. (2019). Attitude of gratitude: Exploring the implementation of a gratitude intervention with college athletes. J. Appl. Sport Psychol. 31, 273-284. doi: 10.1080/10413200. 2018.1498956

García-Alandete, J. (2015). Does meaning in life predict psychological well-being. Eur. J. Couns. Psychol. 3, 89-98. doi: 10.5964/ejcop.v3i2.27

Goldberg, D. P., and Hillier, V. F. (1979). A scaled version of the General Health Questionnaire. Psychol. Med. 9, 139-145. doi: 10.1017/S003329170002 1644

Greenberg, J., and Arndt, J. (2012). “Terror management theory," in Handbook of Theories of Social Psychology, eds A. W. Kruglanski and E. T. Higgins (Thousand Oaks: Sage).

Heckendorf, H., Lehr, D., Ebert, D. D., and Freund, H. (2019). Efficacy of an internet and app- based gratitude intervention in reducing repetitive negative thinking and mechanisms of change in the intervention's effect on anxiety and depression: results from a randomized controlled trial. Behav. Res. Ther. 119:103415. doi: 10.1016/j.brat.2019.103415

Hezomi, H., and Nadrian, H. (2018). What determines psychological wellbeing among Iranian female adolescents? Perceived stress may overshadow all determinants. Health Promot. Perspect. 8, 79-87. doi: 10.15171/hpp.2018.10

Hooker, S. A., Masters, K. S., and Park, C. L. (2018). A meaningful life is a healthy life: A conceptual model linking meaning and meaning salience to health. Rev. Gen. Psychol. 22, 11-24. doi: 10.1037/gpr0000115

Ishikawa, H., Tachimori, H., Takeshima, T., Umeda, M., Miyamoto, K., Shimoda, H., et al. (2018). Prevalence, treatment, and the correlates of common mental disorders in the mid 2010's in Japan: the results of the world mental health Japan 2nd survey. J. Affect. Disord. 241, 554-562. doi: 10.1016/j.jad.2018.08.050 
Juczyński, Z., and Ogińska-Bulik, N. (2009). Narzêdzia pomiaru stresu i radzenia sobie ze stresem [Tools for measuring stress and for coping with stress]. Warsaw: Pracownia Testów Psychologicznych.

Karaś, D., and Cieciuch, J. (2017). Polska adaptacja kwestionariusza dobrostanu (Psychological Well-Being Scales) Caroll Ryff [Polish adaptation of Psychological Well-Being Scales Caroll Ryff]. Rocz. Psychol. 20, 815-835.

Kardas, F., Zekeriya, C. A. M., Eskisu, M., and Gelibolu, S. (2019). Gratitude, hope, optimism and life satisfaction as predictors of psychological well-being. Eurasian J. Educ. Res. 19, 81-100. doi: 10.14689/ejer.2019.82.5

Keyes, C. L., Dhingra, S. S., and Simoes, E. J. (2010). Change in level of positive mental health as a predictor of future risk of mental illness. Am. J. Public Health 100, 2366-2371. doi: 10.2105/AJPH.2010.192245

Keyes, C. L. M. (2007). Promoting and protecting mental health as flourishing: A complementary strategy for improving national mental health. Am. Psychol. 62, 95-108. doi: 10.1037/0003-066X.62.2.95

Killen, A., and Macaskill, A. (2015). Using a gratitude intervention to enhance wellbeing in older adults. J. Happiness Stud. 16, 947-964. doi: 10.1007/s10902-0149542-3

Kleiman, E. M., Adams, L. M., Kashdan, T. B., and Riskind, J. H. (2013). Gratitude and grit indirectly reduce risk of suicidal ideations by enhancing meaning in life: Evidence for a mediated moderation model. J. Res. Pers. 47, 539-546. doi: 10.1016/j.jrp.2013.04.007

Koay, S. H., Ng, A. T., Tham, S. K., and Tan, C. S. (2020). Gratitude intervention on Instagram: an experimental study. Psychol. Stud. 65, 168-173. doi: 10.1007/ s12646-019-00547-6

Korkmaz, H., and Güloğlu, B. (2021). The role of uncertainty tolerance and meaning in life on depression and anxiety throughout Covid-19 pandemic. Pers. Individ. Differ. 179:110952. doi: 10.1016/j.paid.2021.110952

Kossakowska, M., Kwiatek, P., and Stefaniak, T. (2013). Sens w życiu. Polska wersja kwestionariusza MQL [Meaning in Life. Polish Version of MLQ]. Psychol. Jakości Życia 12, 111-131. doi: 10.5604/16441796.1090786

Koydemir, S., Sökmez, A. B., and Schütz, A. (2021). A meta-analysis of the effectiveness of randomized controlled positive psychological interventions on subjective and psychological well-being. Appl. Res. Qual. Life 16, 1145-1185. doi: 10.1007/s11482-019-09788-z

Krok, D. (2015). The Role of Meaning in Life Within the Relations of Religious Coping and Psychological Well-Being. J. Relig. Health 54, 2292-2308. doi: 10. 1007/s10943-014-9983-3

Lambert, N. M., Clark, M. S., Durtschi, J., Fincham, F. D., and Graham, S. M. (2010). Benefits of expressing gratitude: Expressing gratitude to a partner changes one's view of the relationship. Psychol. Sci. 21, 574-580. doi: 10.1177/ 0956797610364003

Lambert, N. M., Gwinn, A. M., Baumeister, R. F., Strachman, A., Washburn, I. J., Gable, S. L., et al. (2013). A boost of positive affect: The perks of sharing positive experiences. J. Soc. Pers. Relat. 30, 24-43. doi: 10.1177/0265407512449400

Lew, B., Chistopolskaya, K., Osman, A., Huen, J. M. Y., Talib, M. A., and Leung, A. N. M. (2020). Meaning in life as a protective factor against suicidal tendencies in Chinese University students. BMC Psychiatry 20, 1-9. doi: 10.1186/s12888020-02485-4

Liang, H., Chen, C., Li, F., Wu, S., Wang, L., Zheng, X., et al. (2020). Mediating effects of peace of mind and rumination on the relationship between gratitude and depression among Chinese university students. Curr. Psychol. 39, 14301437. doi: 10.1007/s12144-018-9847-1

Lin, C. C. (2021). Gratitude and suicidal ideation in undergraduates in Taiwan: The mediating role of self-esteem and meaning in life. Omega - J. Death Dying 84, 177-193. doi: 10.1177/0030222819882845

Lyubomirsky, S., Dickerhoof, R., Boehm, J. K., and Sheldon, K. M. (2011). Becoming happier takes both a will and a proper way: An experimental longitudinal intervention to boost well-being. Emotion 11, 391-402. doi: 10. $1037 / \mathrm{a} 0022575$

Makowska, Z., and Merecz, D. (2001). Ocena zdrowia psychicznego na podstawie badań kwestionariuszami Davida Goldberga. Podrêcznik dla użytkowników kwestionariuszy GHQ12 i GHQ28 [Mental health assessment using David Goldberg's questionnaires. Handbook for GHQ12 and GHQ28 users]. Łódź: Instytut Medycyny Pracy im prof. J. Nofera.

Mishra, P., Pandey, C. M., Singh, U., Gupta, A., Sahu, C., and Keshri, A. (2019). Descriptive statistics and normality tests for statistical data. Ann. Card. Anaesth. 22, 67-72. doi: 10.4103/aca.ACA_157_18
National Health Institute (2019). 2019 National Survey on Drug Use and Health. Avalable online at: https://www.nimh.nih.gov/health/statistics/mental-illness (accessed: 14.07.2021)

O'Leary, K., and Dockray, S. (2015). The effects of two novel gratitude and mindfulness interventions on well-being. J. Altern. Complement. Med. 21, 243-245. doi: 10.1089/acm.2014.0119

Reker, G. T., Birren, J. E., and Svensson, C. M. (2013). "Restoring, Maintaining, and Enhancing Personal Meaning in Life rough Autobiographical Methods," in The human quest for meaning, ed. P. T. P. Wong (New York: Routledge).

Ryff, C. D. (1995). Psychological well-being in adult life. Curr. Dir. Psychol. Sci. 4, 99-104. doi: 10.1111/1467-8721.ep10772395

Ryff, C. D., and Keyes, C. L. M. (1995). The structure of psychological well-being revisited. J. Pers. Soc. Psychol. 69, 719-727. doi: 10.1037/0022-3514.69.4.719

Ryff, C. D., and Singer, B. (1998). The contours of positive human health. Psychol. Inq. 9, 1-28.

Schotanus-Dijkstra, M., Drossaert, C. H., Pieterse, M. E., Boon, B., Walburg, J. A., and Bohlmeijer, E. T. (2017). An early intervention to promote well-being and flourishing and reduce anxiety and depression: A randomized controlled trial. Internet Interv. 9, 15-24. doi: 10.1016/j.invent.2017.04.002

Seligman, M. E. P., and Csikszentmihalyi, M. (2000). Positive psychology: An introduction. Am. Psychol. 55, 5-14. doi: 10.1037/0003-066X.55.1.5

Stagnaro, J. C., Cía, A. H., Gaxiola, S. A., Vázquez, N., Sustas, S., Benjet, C., et al. (2018). Twelve-month prevalence rates of mental disorders and service use in the Argentinean Study of Mental Health Epidemiology. Soc. Psychiatry Psychiatr. Epidemiol. 53, 121-129. doi: 10.1007/s00127-017-1475-9

Steger, M. F., Frazier, P., and Oishi, S. (2006). The Meaning in Life Questionnaire: Assessing the presence of and search for meaning in life. J. Couns. Psychol. 53, 80-93. doi: 10.1037/0022-0167.53.1.80

Steger, M. F., and Kashdan, T. B. (2006). Stability and specificity of meaning in life and life satisfaction over one year. J. Happiness Stud. 8, 161-179. doi: 10.1007/s10902-006-9011-8

van Agteren, J., Iasiello, M., Lo, L., Bartholomaeus, J., Kopsaftis, Z., Carey, M., et al. (2021). A systematic review and meta-analysis of psychological interventions to improve mental wellbeing. Nat. Hum. Behav. 5, 631-652. doi: 10.1038/s41562021-01093-w

Watkins, P. C., Uhder, J., and Pichinevskiy, S. (2015). Grateful recounting enhances subjective well-being: The importance of grateful processing. J. Posit. Psychol. 10, 91-98. doi: 10.1080/17439760.2014.927909

Weiss, L. A., Westerhof, G. J., and Bohlmeijer, E. T. (2016). Can we increase psychological well being? The effects of interventions on psychological wellbeing: A meta-analysis of randomized controlled trials. PLoS One 11:e0158092. doi: 10.1371/journal.pone.0158092

Wood, A. M., Joseph, S., and Maltby, J. (2009). Gratitude predicts psychological well-being above the big five facets. Pers. Individ. Differ. 46, 443-447. doi: 10.1016/j.paid.2008.11.012

World Health Organization (2004). Promoting mental health: Concepts, emerging evidence, practice: Summary report. Geneva: World Health Organization.

Xiang, Y., and Yuan, R. (2021). Why do people with high dispositional gratitude tend to experience high life satisfaction? A broaden-and-build theory perspective. J. Happiness Stud. 22, 2485-2498. doi: 10.1007/s10902-020-00 $310-\mathrm{Z}$

Conflict of Interest: The authors declare that the research was conducted in the absence of any commercial or financial relationships that could be construed as a potential conflict of interest.

Publisher's Note: All claims expressed in this article are solely those of the authors and do not necessarily represent those of their affiliated organizations, or those of the publisher, the editors and the reviewers. Any product that may be evaluated in this article, or claim that may be made by its manufacturer, is not guaranteed or endorsed by the publisher.

Copyright (c) 2022 Czyżowska and Gurba. This is an open-access article distributed under the terms of the Creative Commons Attribution License (CC BY). The use, distribution or reproduction in other forums is permitted, provided the original author(s) and the copyright owner(s) are credited and that the original publication in this journal is cited, in accordance with accepted academic practice. No use, distribution or reproduction is permitted which does not comply with these terms. 